\title{
Medicinal Effects of Bromelain (Ananas comosus) Targeting Oral Environment as an Anti-oxidant and Anti-inflammatory Agent
}

\author{
Jung-Ha Lee ${ }^{1}$, Jae-Bong Lee ${ }^{2}$, Jin-Tae Lee ${ }^{2}$, Hae-Ryoun Park ${ }^{1}$, Jin-Bom Kim ${ }^{1, *}$ \\ ${ }^{1}$ Pusan National University, South Korea \\ ${ }^{2}$ Daegu Haany University, South Korea \\ *Corresponding author: jbomkim@pusan.ac.kr
}

Received November 12, 2018; Revised December 17, 2018; Accepted December 28, 2018

\begin{abstract}
Bromelain is obtained from Ananas comosus and is of significant clinical interest. Many studies have demonstrated bromelain's ability to treat immune-mediated conditions including reduction of platelet aggregation, angina pectoris and surgical trauma. ROS elimination were evaluated using a variety of anti-oxidation effect tests containing DPPH assay, ABTS + radical scavenging assay, hydrogen peroxide scavenging assay. Western blotting analysis and RT-PCR were used to investigate an anti-inflammatory agent in LPS-induced RAW cells. Treatment with bromelain exhibited significant scavenging abilities on superoxide radicals compared with control. As results of analyzing iNOS and COX-2 band appearance according to bromelain treatment, it inhibited the band expression dose-dependently. Also bromelain inhibits the phosphorylated-MAP kinases signaling pathways. Furthermore, it reduced c-Fos, phosphorylation of c-Jun and c-Jun. According to the results, it is demonstrated that bromelain of Ananas comosus extract have significant anti-inflammatory ability as well as antioxidant ability.
\end{abstract}

Keywords: bromelain, anti-oxidant effect, anti-inflammatory effect, public oral health

Cite This Article: Jung-Ha Lee, Jae-Bong Lee, Jin-Tae Lee, Hae-Ryoun Park, and Jin-Bom Kim, "Medicinal Effects of Bromelain (Ananas comosus) Targeting Oral Environment as an Anti-oxidant and Anti-inflammatory Agent.” Journal of Food and Nutrition Research, vol. 6, no. 12 (2018): 773-784. doi: 10.12691/jfnr-6-12-8.

\section{Introduction}

Bromelain has been studied for its anti-thrombotic and anti-metastatic properties. A study has shown that bromelain can inhibit metastasis-associated platelet aggregation. [1] In addition, bromelain has been shown to interact with effectors and pathways involved in physiological processes including inflammation and immune response. [2] Thus, the therapeutic potential of bromelain, alone or in combination with other agents, has been tested in both preclinical and clinical settings.

The beneficial effects of bromelain have been suggested or proven in a variety of inflammatory diseases and models. These include immunologically mediated arteriosclerosis in rat aortic allografts [3], allergic encephalomyelitis (EAE) model of multiple sclerosis [4], collagen-induced arthritis in the rat. [5] In study, bromelain had an efficacy similar to standard anti-inflammatory drugs. For example, a dose of $10 \mathrm{mg} / \mathrm{kg}$ bromelain had an activity similar to $0.3 \mathrm{mg} / \mathrm{kg}$ dexamethasone in a carrageenan-induced pleurisy model in the rat. [6]

The beneficial effects of bromelain are attributable to its multiple constituents. Although bromelain is comprised of sulfhydryl-containing proteolytic enzymes, it contains escharase, a non-proteolytic component with wound debriding effects. [7] Furthermore, pleiotropic therapeutic effects of bromelain are considered due to complex natural mixture of related cysteine proteinases, proteinase inhibitors, phosphatases, glucosidases, peroxidases. [8] The beneficial therapeutic effects of bromelain have also been suggested or proven in preclinical animal models of inflammation as well as in human inflammatory bowel disease and arthritis. Bromelain has also been shown to have beneficial effects in a variety of inflammatory diseases in both humans and mice. [9]

Reactive oxygen species (ROS) has gained significant recognition over the past years. [10] are chemically reactive oxygen containing molecules, including the superoxide anion radical $\left(. \mathrm{O}_{2}{ }^{-}\right)$, the hydroxyl radical (.OH), hydrogen peroxide $\left(\mathrm{H}_{2} \mathrm{O}_{2}\right)$, and nitric oxide (NO). ROS are constantly produced in cells as a result of cellular metabolism. [11] They are essential for life because they are involved in cell signaling, and are used by phagocytes for their bactericidal action. Recently, increasing evidence has highlighted that overproduction of ROS and free radicals may contribute to a variety of pathological effects and can induce many diseases including, cancer, atherosclerosis, and rheumatoid arthritis. [12] Currently, plant-sourced antioxidant agents have been attracting interest because they can protect the human body from diseases induced by free radicals with little or no side effects. Antioxidant materials can decrease oxidative 
stress by ending the oxidative chain reaction, thereby inhibiting oxidative damage.

Stomatitis is a disease that causes inflammation in the mouth mucosa (tongue, gums and lips) and is caused by infection with bacterial infections, fungal infections, viral infections, immune oral mucosal diseases such as recurrent aphasic oral ulcers, and pemphigus. The causes of oral mucous diseases and stomatitis are not precisely known, but hormonal changes, vitamin B12 deficiency, iron and folate deficiency, allergies, and toothpaste ingredients can cause oral mucosal disease. An oral mucous membrane disease is characterized by a stiff or burning feeling in the mouth, a feeling of pain when eating food, and an unpleasant smell in the mouth.

Periodontal disease is caused by the toxins derived from the periodontal pathogens and progresses more deeply as these pathogens penetrate into the periodontal tissue. The inflammation caused by the toxins and pathogens, as well as the progression of the immune reaction, lead to an acute and chronic destruction of periodontal tissue. Tumor necrosis factor $\alpha(\mathrm{TNF}-\alpha)$ is a cytokine that is involved in the inflammatory response. This substance is interrelated and stimulates or enhances the production of inflammation-related substances, and is important factors in inflammation. Therefore, in order to prevent and treat periodontal disease, it is important to control both the periodontal bacteria, and the inflammation that arises as a result of the generation of immune response mediators that occurs in response to the bacteria.

The purpose of this study was to assess the antioxidant ability of a preparation of bromelain from Ananas comosus using in vitro free radical scavenging assays. Further, the anti-inflammatory activity of bromelain was examined by assessing its effect on the protein and gene expression of inflammatory molecules using western blotting and RT-PCR. Furthermore, this study aimed to demonstrate how bromelain might serve to reduce oral inflammatory diseases, such as stomatitis, and to explore the possibility of it being used to treat the more severe disease periodontitis.

\section{Material and Methods}

\subsection{Materials}

\subsubsection{Anti-oxidative Effects}

DPPH, ABTS, hydrogen peroxide and ascorbic acid were purchased from Sigma Chemical Co. (St. Louis, MO, USA). BHA and BHT were from Junsei Chemical Co. (Chuo-ku, Tokyo, Japan).

\subsubsection{Anti-inflammatory Effects}

RAW 264.7 cells were obtained from the Korean Cell Line Bank (KCLB, Seoul, Korea). Griess reagent, RPMI 1640, DMEM, FBS, penicillin/streptomycin were purchased from Gibco BRL (Grand Island, NY, USA). LPS, 3-[4, 5dimethylthiazol-2-yl]-2.5-diphenyl tetrazolium bromide (MTT), acrylamide and N, N'-bis-methylene-acrylamide were from Sigma Chemical Co. Antibodies against p-ERK, p-JNK, p-P38, c-Jun, c-Fos, and anti- $\beta$-actin monoclonal antibody, and secondary antibodies were purchased from Santa Cruz Biotechnology, Inc (Dallas, Texas, USA). The primers used for amplification of iNOS, COX-2, TNF- $\alpha$ and $\beta$-actin were purchased from Bionics, Inc (Emeryville, CA, USA). RAW 264.7 cellswere obtained from the Korean Cell Line Bank (KCLB, Seoul, Republic of Korea).

\subsection{Preparation of Crude Extract from Ananas comosus and Its Purification}

In order to extract bromelain, Ananas comosus was purchased from Del Monte, Inc. (Philippines). The stem and bark of Ananas comosus were separated from the fleshy fruit and portions were then cut into small pieces and dried at room temperature. Following this, 70\% (v/v) ethanol was added for $48 \mathrm{~h}$ to extract the enzyme proteins, after which the supernatant was collected by centrifugation. A solution of $70 \%$ saturated ammonium sulfate was then added to coagulate and precipitate the enzyme proteins and the extract was centrifuged. The crude extract was then dialyzed against $70 \%$ (v/v) ethanol, followed by chromatography on a DEAE-cellulose column at a flow rate of $0.7 \mathrm{~mL} / \mathrm{min}$ and elution with a linear gradient of $0 \sim 1 \mathrm{M} \mathrm{NaCl}$. The active fractions were pooled and chromatographed on a G-150 gel filtration column at a flow rate of $0.4 \mathrm{~mL} / \mathrm{min}$ collecting $4 \mathrm{~mL}$ fractions. The active fractions were collected, concentrated, and lyophilized. The purified bromelain was stored in a freezer at $-18^{\circ} \mathrm{C}$, and prior to each experiment a solution was freshly prepared by dissolving bromelain in distilled water at a concentration of $1000 \mu \mathrm{g} / \mathrm{mL}$, filtered and further diluted to achieve required final concentration.

\subsection{ABTS Radical Scavenging Assay}

The ABTS radical scavenging assay was measured using the method described by Re et al with minor modifications. [13] The ABTS radical cation was generated by mixing $7 \mathrm{mM}$ ABTS and $2.4 \mathrm{mM}$ potassium persulfate $\left(\mathrm{K}_{2} \mathrm{~S}_{2} \mathrm{O}_{8}\right)$ and incubating for $12 \mathrm{~h}$ at room temperature in the dark. Before use, the ABTS solution was diluted with ethanol to give an absorbance of $0.706 \pm$ 0.001 at $734 \mathrm{~nm}$ using a spectrophotometer. The positive controls contained BHT instead of the test sample. The scavenging activity of ABTS free radical was calculated as:

$$
\begin{aligned}
& \text { ABTS radical scavenging ability }(\%) \\
& =\left(1-\text { sample } A_{734 n m} / \text { control } A_{734 n m}\right) \times 100 .
\end{aligned}
$$

All determinations were performed triplicate.

\subsection{DPPH Radical Scavenging Assay}

The scavenging capacity of bromelain for the DPPH radical was determined using a slight modification of the method reported by Blois. [14] An aliquot of $100 \mu \mathrm{L}$ of a $0.2 \mathrm{mM}$ DPPH solution in ethanol and $100 \mathrm{uL}$ of the bromelain extract at various concentrations were mixed. The mixture was shaken vigorously and allowed to reach a steady state at room temperature for $30 \mathrm{~min}$. Decolorization of DPPH was determined by measuring its absorbance at $515 \mathrm{~nm}$ using an ELISA reader. The 
positive control using BHA was prepared in a similar way as the test group.

The radical scavenging capacity of the tested samples was determined using the following equation.

$$
\begin{aligned}
& \text { DPPH radical scavenging ability }(\%) \\
& =\left(1-\text { sample } A_{515 \mathrm{~nm}} / \text { control } A_{515 \mathrm{~nm}}\right) \times 100 .
\end{aligned}
$$

All determinations were performed in triplicate.

\subsection{Hydrogen Peroxide $\left(\mathrm{H}_{2} \mathrm{O}_{2}\right)$ Scavenging Activity}

The hydrogen peroxide scavenging activity was measured based on the method described by Jayaprakasha. [15] A solution of hydrogen peroxide was prepared in phosphatebuffer saline (PBS at $\mathrm{pH}$ 7.4). Various concentrations of the samples (in a final volume of $1 \mathrm{~mL}$ ) were added to 2 $\mathrm{mL}$ of hydrogen peroxide solution in PBS. After $10 \mathrm{~min}$ the absorbance was measured at $230 \mathrm{~nm}$. Ascorbic acid was used as the positive control. The hydroxyl radical inhibition percentage was calculated according to the given formula:

$$
\begin{aligned}
& \text { Hydrogen peroxide }\left(\mathrm{H}_{2} \mathrm{O}_{2}\right) \text { scavengingability }(\%) \\
& =\left(1-\text { sample } A_{230 \mathrm{~nm}} / \text { control } A_{230 \mathrm{~nm}}\right) \times 100 .
\end{aligned}
$$

All determinations were performed in triplicate.

\subsection{Superoxide Dismutase (SOD) like Activity}

The SOD-like activity was measured based on the method reported by Marklund. [16] The reaction mixture was prepared by mixing $0.2 \mathrm{~mL}$ of the bromelain solution, $2.6 \mathrm{~mL}$ of the Tris-CI buffer (50 mM TRIZMA+ $10 \mathrm{mM}$ EDTA , pH 8.5), and $0.2 \mathrm{~mL}$ of $7.2 \mathrm{mM}$ pyrogallol, and allowing it to stand at $25^{\circ} \mathrm{C}$ for $10 \mathrm{~min}$. The oxidized pyrogallol was then measured at $420 \mathrm{~nm}$ using a spectrophotometer after stopping the reaction by adding $0.1 \mathrm{~mL}$ of $1.0 \mathrm{~N} \mathrm{HCl}$. Ascorbic acid was used as the positive control. All determinations were performed in triplicate. A decrease in absorbance of the reaction mixture indicated increased superoxide anion scavenging activity. The capability to scavenge the superoxide radical was calculated using the following equation:

$$
\begin{aligned}
& \text { Superoxide dismutase }(S O D) \text { likeability }(\%) \\
& =\left(1-\text { sample } A_{420 \mathrm{~nm}} / \text { control } A_{420 \mathrm{~nm}}\right) \times 100 .
\end{aligned}
$$

All determinations were performed in triplicate.

\subsection{Cell Nitric Oxide (NO) Radical Inhibition Assay}

The nitrite-scavenging ability was measured based on the method described by Grayand and Dugan with some modifications. [17] RAW 264.7 cells were pre-treated with the indicated concentrations of bromelain for $24 \mathrm{~h}$, after which $1 \mu \mathrm{g} / \mathrm{mL}$ of LPS was added for an additional 4 $\mathrm{h}$ to stimulate the macrophages. Following this, $1 \mathrm{~mL}$ of each sample was added to $2 \mathrm{~mL}$ of $1 \mathrm{mM} \mathrm{NaNO}_{2}$, followed by the addition of $10 \mathrm{~mL} 0.1 \mathrm{~N} \mathrm{Hcl}(\mathrm{pH} \mathrm{1.2)}$ and solution was allowed to react at $37^{\circ} \mathrm{C}$ for $1 \mathrm{hr}$. One $\mathrm{mL}$ of the reaction mixture was added to $5 \mathrm{~mL}$ of $2 \%$ acetic acid and $0.4 \mathrm{~mL}$ Griess reagent. The mixture was allowed to react for $15 \mathrm{~min}$ at room temperature, after which its absorbance was measured at $540 \mathrm{~nm}$ using a UV spectrophotometer. A blank was prepared by adding 0.4 $\mathrm{mL}$ of distilled water instead of the Griess reagent. The inhibitory effect of bromelain on NO production was determined by analyzing the NO level. All assays were performed in triplicate.

The NO scavenging activity of each sample/standard solution was calculated using the following equation:

$$
\begin{aligned}
& \text { NO radical scavenging ability }(\%) \\
& =\left(1-\text { sample } A_{420 \mathrm{~nm}} / \text { control } A_{420 \mathrm{~nm}}\right) \times 100 .
\end{aligned}
$$

All determinations were performed in triplicate.

\subsection{Western Blotting Analysis}

RAW 264.7 cells treated with bromelain were washed twice with PBS and centrifuged at 2,000 rpm for $10 \mathrm{~min}$. Protein extracts were prepared in RIPA lysis buffer. Cells were placed on ice for 20 min to allow lysis, after which the lysate was centrifuged at $10,000 \mathrm{rpm}$ for $20 \mathrm{~min}$ at $4^{\circ} \mathrm{C}$. The lysates were centrifuged at $14,000 \mathrm{rpm}$ for $15 \mathrm{~min}$ at $4^{\circ} \mathrm{C}$, and SDS and sodium deoxycholic acid were then added. Protein samples $(40 \mu \mathrm{g})$ were electro-blotted onto a nitrocellulose membrane following separation using 8-12\% SDS-polyacrylamide gel electrophoresis. The blotted membrane was incubated overnight at $4{ }^{\circ} \mathrm{C}$ with $1 \%(\mathrm{w} / \mathrm{v})$ skimmed milk in TBS and then incubated with the primary antibody. The secondary antibody was applied, and the membrane was incubated for 2 hours at room temperature. After washing the membrane with TBST, the membrane was developed with electro-chemiluminescence (ECL) solution for 5 minutes. Immuno-reactive bands were detected using an EZ-Capture II cooled CCD camera system.

\subsection{Isolation of RNA and Reverse Transcription PCR}

The quality of total RNA was determined by evaluating the $A_{260} / A_{280}$ ratio. To prepare a cDNA pool from each RNA sample, total RNA $(2 \mu \mathrm{g} / \mu \mathrm{L})$ was reverse transcribed using a Transcriptor First Strand cDNA Synthesis Kit from Roche Molecular Biochemicals (Penzberg, Bavaria, Germany). Each cDNA pool was stored at $-20^{\circ} \mathrm{C}$ until the reverse transcription PCR analysis was performed. The cDNA obtained was amplified with primers having the following sequences: TNF- $\alpha, 5$-ATGAGCACTGAAA GCAGATC-3' and 3'-CAGACCCGTCCAGATGAAAC-5'; iNOS, 5'-CGAAACGCTTCACTTCCAA-3' and 3'-TCGG TGTCGTTATATCCGAGT-5'; COX-2, 5'-GAACATTG TGAACAACATCCC-3' and 3'-TTGGTGGCATACATC ATCAGA-5'; $\beta$-actin, 5'-GTGGGCCGCTCTAGGCAC CAA-3' and 3'-CTCTTTGATGTCACGCACGATTTC-5'. Specific primers for $\beta$-actin were used as a control. The resulting products were analyzed by electrophoresis on $2 \%$ agarose gels and stained with ethidium bromide. PCR was carried out for 40 cycles using the following conditions: denaturation at $94^{\circ} \mathrm{C}$ for $30 \mathrm{~s}$, annealing at 
$55^{\circ} \mathrm{C}$ for $30 \mathrm{~s}$, and extension at $72^{\circ} \mathrm{C}$ for $1 \mathrm{~min}$. The final products were separated by electrophoresis on a $2 \%$ agarose gel. The luminescence intensity of the DNA bands was measured using an ATTO densitometer with Molecular Analyst software (Taito-ku, Tokyo, Japan).

\subsection{Statistical Analysis}

The data are representative of three or more experiments performed under identical conditions and are expressed as the mean \pm standard error of the mean. Differences between means were tested for significance by a one-way analysis of variance test using a statistical software package (SPSS version 22.0; SPSS Inc., Chicago, IL, USA). A p value of less than 0.05 was considered statistically significant.

\section{Results and Disscusion}

\subsection{Preparation of Crude Extract from Ananas comosus and Its Purification}

The extract obtained from Ananas comosus was dialyzed against $70 \%$ ethanol and was concentrated. The concentrated extract was subjected to ion-exchange chromatography on a DEAE-cellulose column; five fractions were obtained, with the active protein eluting with $\sim 0.5 \mathrm{M} \mathrm{NaCl}$. At this step, the yield was approximately 57\%. The active fractions were gel filtered on a G-150 column, after which fractions containing the active enzyme were concentrated and lyophilized. At this step, the yield was approximately $49 \%$ and the fold purification was 17 , which was higher than that reported by Silverstein et al. (14.2 fold). [18]

\subsection{ABTS Radical Scavenging Assay}

ABTS is an excellent tool for determining the antioxidant activity of hydrogen-donating antioxidants and of chain-breaking antioxidants and can be used to measure the antioxidant effects of drugs. Rice-Evans has demonstrated that the ABTS assay can be used to measure the antioxidant activity of a broad range of substances. [19] The ABTS radical scavenging ability increased as the bromelain concentration was increased up to $1000 \mu \mathrm{g} / \mathrm{mL}$ (Figure 2A). At a concentration of $500 \mu \mathrm{g} / \mathrm{mL}$, the scavenging ability was $95.58 \%$, which compared very favorably with that of the positive control (BHT, 99.23\% scavenging ability at $500 \mu \mathrm{g} / \mathrm{mL}$ ).

\subsection{DPPH Radical Scavenging Assay}

The DPPH radical is commonly used to measure antioxidant ability. The color of the solution changes from purple to yellow color, and the intensity of color developed is proportional to the number of moles of the stabilized molecule. [20] The DPPH radical scavenging ability increased as the bromelain concentration was increased up to $500 \mu \mathrm{g} / \mathrm{mL}$ (Figure 2B). At a concentration of $500 \mu \mathrm{g} / \mathrm{mL}$, the scavenging ability was $68.07 \%$, which compared very favorably with that of the positive control (BHA, 99.78\% scavenging ability at $500 \mu \mathrm{g} / \mathrm{mL}$ ).

\subsection{Hydrogen Peroxide $\left(\mathrm{H}_{2} \mathrm{O}_{2}\right)$ Scavenging Activity}

Hydrogen peroxide can be converted into singlet oxygen and a hydroxyl radical, therefore, hydroxyl peroxide is a very powerful oxidizing agent. When we tested the scavenging activity for hydrogen peroxide, bromelain removed the hydroxyl radical in a dosedependent manner, with an activity almost similar to that of ascorbic acid, which is known to be a representative antioxidant for the hydrogen radical. The hydrogen peroxide scavenging activity increased as the bromelain concentration was increased up to $1000 \mu \mathrm{g} / \mathrm{mL}$ (Figure 2C). At a concentration of $500 \mu \mathrm{g} / \mathrm{mL}$, the hydrogen peroxide scavenging activity was 92.89\%, which compared very favorably with that of the positive control (ascorbic acid, 99.34\% scavenging ability at $500 \mu \mathrm{g} / \mathrm{mL}$ ).

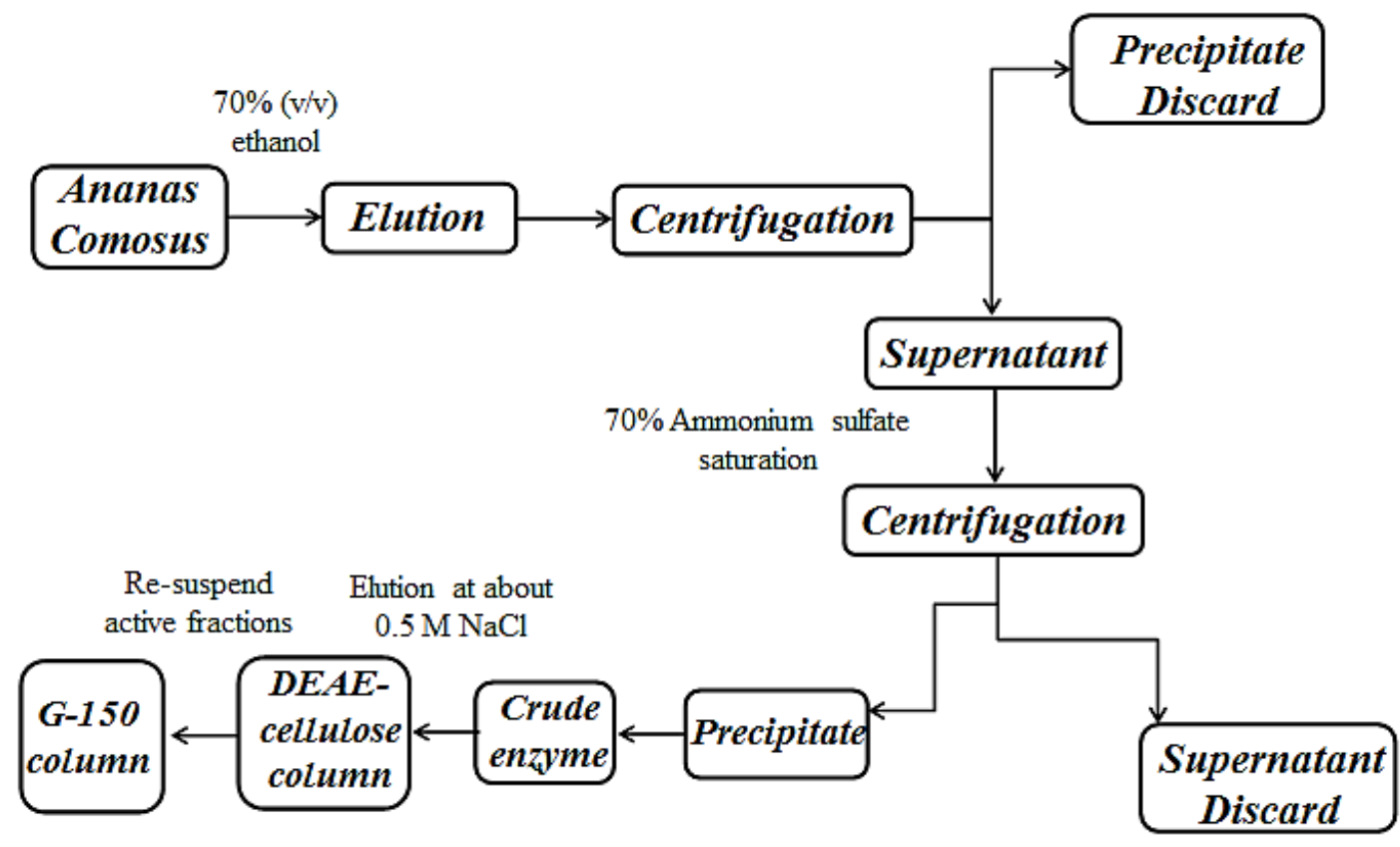

Figure 1. Procedure used for the purification of bromelain from Ananas comosus 


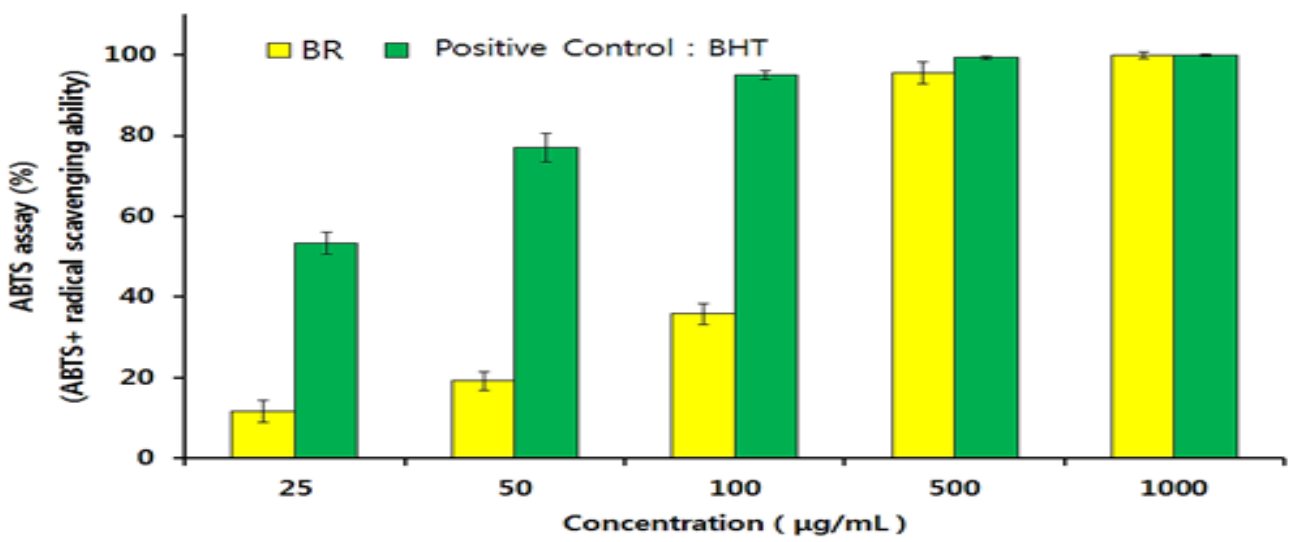

A
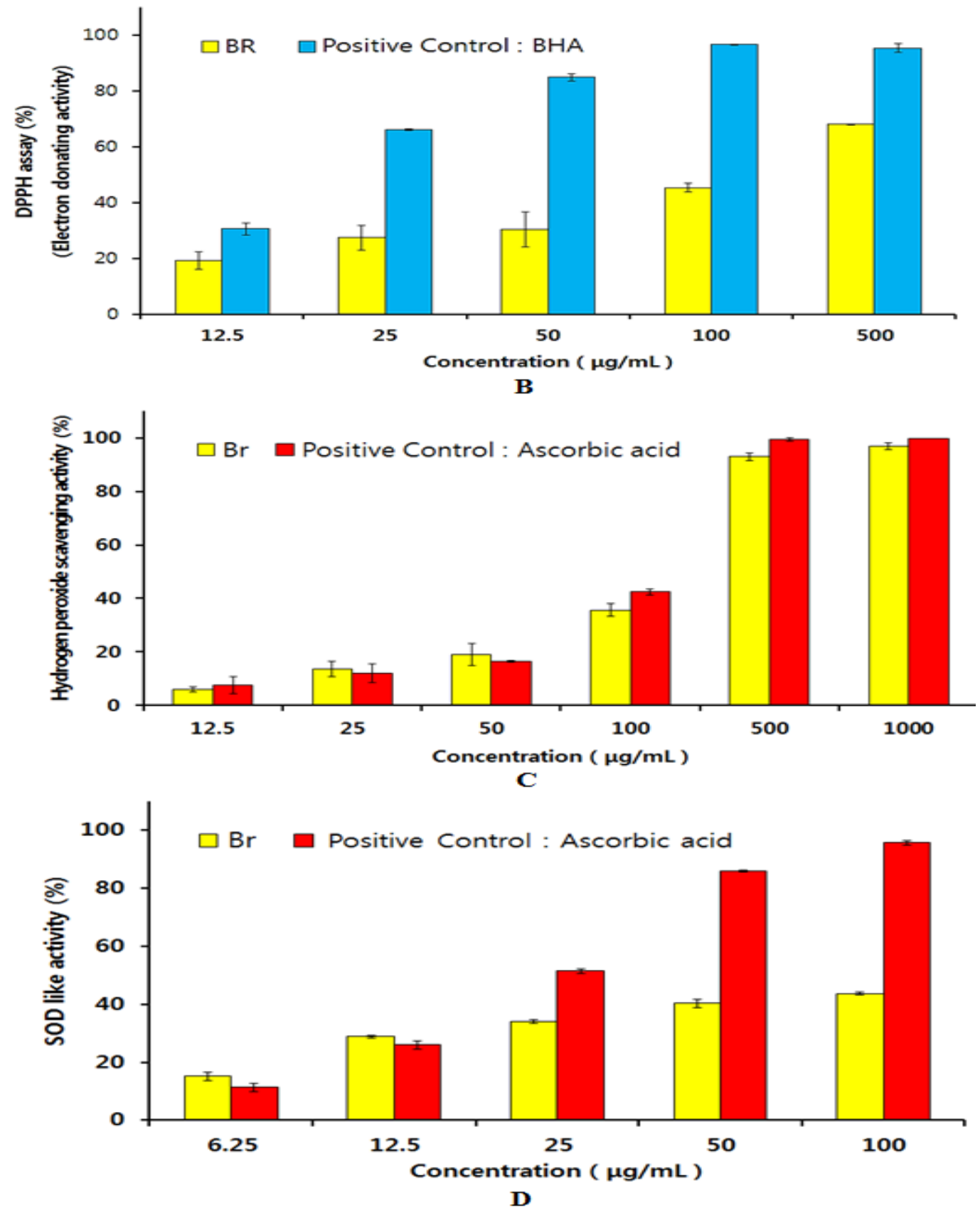

Figure 2. (A) The ABTS radical scavenging activity of bromelain. The ABTS radical scavenging ability was calculated as $(\%)=(1-$ sample $\mathrm{A}_{734 \mathrm{~nm}} /$ control $\left.\mathrm{A}_{734 \mathrm{~nm}}\right) \times 100$. (B) The DPPH radical scavenging activity of bromelain. The DPPH radical scavenging ability was calculated as (\%) = (1 - sample $A_{515 n m} /$ control $A_{515 n m}$ x 100 . (C) The hydrogen peroxide scavenging activity of bromelain. The hydrogen peroxide scavenging ability was calculated as $(\%)=\left(1-\right.$ sample $\mathrm{A}_{230 \mathrm{~nm}} /$ control $\left.\mathrm{A}_{230 \mathrm{~nm}}\right) \times 100$. (D) The superoxide dismutase (SOD)-like activity of bromelain. The SOD-like ability was calculated as $(\%)=\left(1-\right.$ sample $\mathrm{A}_{420 \mathrm{~nm}} /$ control $\left.\mathrm{A}_{420 \mathrm{~nm}}\right) \times 100$. All data are expressed as mean \pm standard deviation $(\mathrm{n}=3)$. $P<0.05$, compared to the positive control 
Table 1. ABTS, DPPH, hydrogen peroxide $\left(\mathrm{H}_{2} \mathrm{O}_{2}\right)$, and superoxide dismutase (SOD) scavenging abilities of bromelain

\begin{tabular}{|c|c|c|c|c|c|c|c|c|}
\hline \multirow[b]{2}{*}{ Treatment } & \multicolumn{2}{|c|}{ ABTS radical } & \multicolumn{2}{|c|}{ DPPH radical } & \multicolumn{2}{|c|}{ Hydrogen peroxide $\left(\mathrm{H}_{2} \mathrm{O}_{2}\right)$} & \multicolumn{2}{|c|}{ Superoxide dismutase (SOD) } \\
\hline & $\begin{array}{c}\text { Scavenging } \\
\text { ability (\%) } \\
(500 \mu \mathrm{g} / \mathrm{mL})\end{array}$ & $\begin{array}{l}\text { IC }_{50} \text { value } \\
(\mu \mathrm{g} / \mathrm{mL})\end{array}$ & $\begin{array}{c}\text { Scavenging } \\
\text { ability (\%) } \\
(500 \mu \mathrm{g} / \mathrm{mL})\end{array}$ & $\begin{array}{l}\text { IC }_{50} \text { value } \\
(\mu \mathrm{g} / \mathrm{mL})\end{array}$ & $\begin{array}{c}\text { Scavenging } \\
\text { ability (\%) } \\
(500 \mu \mathrm{g} / \mathrm{mL})\end{array}$ & $\begin{array}{l}\mathrm{IC}_{50} \text { value } \\
(\mu \mathrm{g} / \mathrm{mL})\end{array}$ & $\begin{array}{l}\text { Scavenging } \\
\text { ability (\%) } \\
(100 \mu \mathrm{g} / \mathrm{mL})\end{array}$ & $\begin{array}{l}\text { IC }_{50} \text { value } \\
(\mu \mathrm{g} / \mathrm{mL})\end{array}$ \\
\hline Bromelain & $95.58 \pm 0.026^{\mathrm{a}}$ & $131.2 \pm 0.373^{\mathrm{a}}$ & $67.07 \pm 0.165^{\mathrm{a}}$ & $145.9 \pm 0.156^{\mathrm{a}}$ & $92.89 \pm 0.126^{\mathrm{a}}$ & $124.3 \pm 0.904^{\mathrm{a}}$ & $43.73 \pm 0.506^{\mathrm{a}}$ & $147.9 \pm 0.435^{\mathrm{a}}$ \\
\hline $\begin{array}{l}\text { Positive } \\
\text { Control }\end{array}$ & $\begin{array}{l}99.23 \pm 0.005^{\mathrm{b}} \\
(\mathrm{BHT})\end{array}$ & $20.58 \pm 0.032^{\mathrm{b}}$ & $\begin{array}{c}99.78 \pm 0.240^{\mathrm{b}} \\
(\mathrm{BHA})\end{array}$ & $17.02 \pm 0029^{b}$ & $\begin{array}{l}99.34 \pm 0.535^{\mathrm{b}} \\
\text { (ascorbic acid) }\end{array}$ & $111.9 \pm 0.321^{\mathrm{b}}$ & $\begin{array}{l}95.74 \pm 0.726^{\mathrm{b}} \\
\text { (ascorbic acid) }\end{array}$ & $22.07 \pm 0.292^{b}$ \\
\hline
\end{tabular}

All data are expressed as mean \pm SD $(n=3)$. The different letters in each column denote a statically significant difference compared to the positive control group at $p<0.05$.

\subsection{Superoxide Dismutase (SOD) like Activity}

SOD is an antioxidant enzyme, which is important in the body's defense against reactive oxygen species. The enzyme exists in all species and can catalyze the production of $\mathrm{H}_{2} \mathrm{O}_{2}$ from the very harmful superoxide anion radical. Furthermore, SOD is gaining a lot of attention as a medicinal material that can be used to prevent skin aging.

SOD-like activity increased as the bromelain concentration was increased up to $100 \mu \mathrm{g} / \mathrm{mL}$ (Figure 2D). At a concentration of $100 \mu \mathrm{g} / \mathrm{mL}$, the SOD-like activity was $43.73 \%$ which compared favorably with that of the positive control (ascorbic acid, 95.74\% scavenging ability at $100 \mu \mathrm{g} / \mathrm{mL})$.

The half maximal inhibitory concentration $\left(\mathrm{IC}_{50}\right)$ is a value that represents ability of a molecule to inhibit a biochemical function. This quantitative value indicates how much of a substance is needed to inhibit a biological process by half. It is often used as a measure of the potency of an antagonist drug. The $\mathrm{IC}_{50}$ values for ABTS, $\mathrm{DPPH}, \mathrm{H}_{2} \mathrm{O}_{2}$, and SOD were $131.2 \pm 0.373,145.9 \pm 0.156$, $124.3 \pm 0.904$ and $147.9 \pm 0.435 \mu \mathrm{g} / \mathrm{mL}$, respectively. Among the various parameters measured here, the $\mathrm{IC}_{50}$ for the hydrogen peroxide scavenging activity of $124.3 \pm$ $0.904 \mu \mathrm{g} / \mathrm{mL}$, which was very similar to that of the positive control group (ascorbic acid), and showed the most effective radical scavenging ability.

\subsection{Cell Nitric Oxide (NO) Radical Inhibition Assay}

Inducible nitric oxide synthase (iNOS) plays a regulatory role in the expression of pro-inflammatory mediators in inflammation. iNOS-derived $\mathrm{NO}$ is involved in various pathological conditions such as inflammation and auto-immune diseases, and leads to cellular injury. Suppression of NO production is believed to be closely linked with the action of anti-inflammatory agents. [21] The NO radical scavenging ability of bromelain increased as the concentration was increased up to $5000 \mu \mathrm{g} / \mathrm{mL}$ (Figure 3A). At $5000 \mu \mathrm{g} / \mathrm{mL}$ bromelain, the $\mathrm{NO}$ radical scavenging ability was $56.12 \%$.

\subsection{Western Blotting Analysis}

\subsubsection{Effects of Bromelain on the iNOS and COX-2 Expression in LPS-stimulated RAW 264.7 Cells}

The ability of bromelain to suppress iNOS and COX-2 expression in RAW 264.7 cells was found to occur in a dose-dependent manner. COX-2 is one of the most well-recognized molecular targets for chemoprevention, and is found to be abnormally upregulated in many premalignant and malignant tissues. [22] In addition, it has been shown that topical application of bromelain inhibited COX-2 expression in mouse skin papillomas stimulated by DMBA-TPA (7,12-dimethylbenz(a)anthracene-initiated and 12-O-tetradecanoylphorbol-13-acetate). [23] Nitric oxide (NO) is an important intracellular and intercellular signaling molecule that is involved in the regulation of diverse physiological and pathophysiological mechanisms in the cardiovascular, nervous, and immunological systems. It acts as a biological mediator similar to neurotransmitters in the neuronal system, can regulate blood vessel tone in the vascular system, and is an important host defense effector in the immune system. [24] On the other hand, it is a free oxygen radical (NO.) that can act as a cytotoxic agent in pathological processes, particularly in inflammatory disorders. [25] Inhibition of inducible nitric oxide synthase (iNOS) may therefore be benefit for the treatment of inflammatory diseases. Western blotting for iNOS and COX-2 showed that bromelain inhibited LPS-induced iNOS and COX-2 expression in a dose-dependent manner (over the range 6.26-50 $\mu \mathrm{g} / \mathrm{mL}$ ) (Figure 3B).

\subsubsection{Effects of Bromelain on the Phosphorylation of MAP Kinases in LPS-stimulated RAW 264.7 Cells}

The effect of bromelain on the phosphorylation of MAP kinases was examined in LPS-stimulated RAW 264.7 cells. P38 MAP kinase is a member of the class of mitogen activated protein kinases that is responsive to stress stimuli such as ultraviolet irradiation, heat shock, apoptosis, and autophagy. JNKs were originally identified as kinases that bind and phosphorylate c-Jun on Ser-63 and Ser-73. A positive feedback circuit is known to be involved in cell death as a phospho-enzyme that controls the balance of signal flow between ERK and JNK course on the concentration of active oxygen. JNK is phosphorylated by upstream MAPK kinases and in turn, phosphorylates and activates its major substrate c-Jun. Bromelain significantly suppressed the levels of p-ERK in LPS-induced RAW 264.7 cells, showing an approximately $38.87 \%$ inhibition at $6.25 \mu \mathrm{g} / \mathrm{mL}$ (Figure 3C). In addition, bromelain also significantly reduced the phosphorylation of both JNK and p-38 at concentrations ranging from $6.25-50 \mu \mathrm{g} / \mathrm{mL}$. From the above data, we conclude that bromelain inhibits the LPS-induced activation of MAP kinase signaling pathways. 

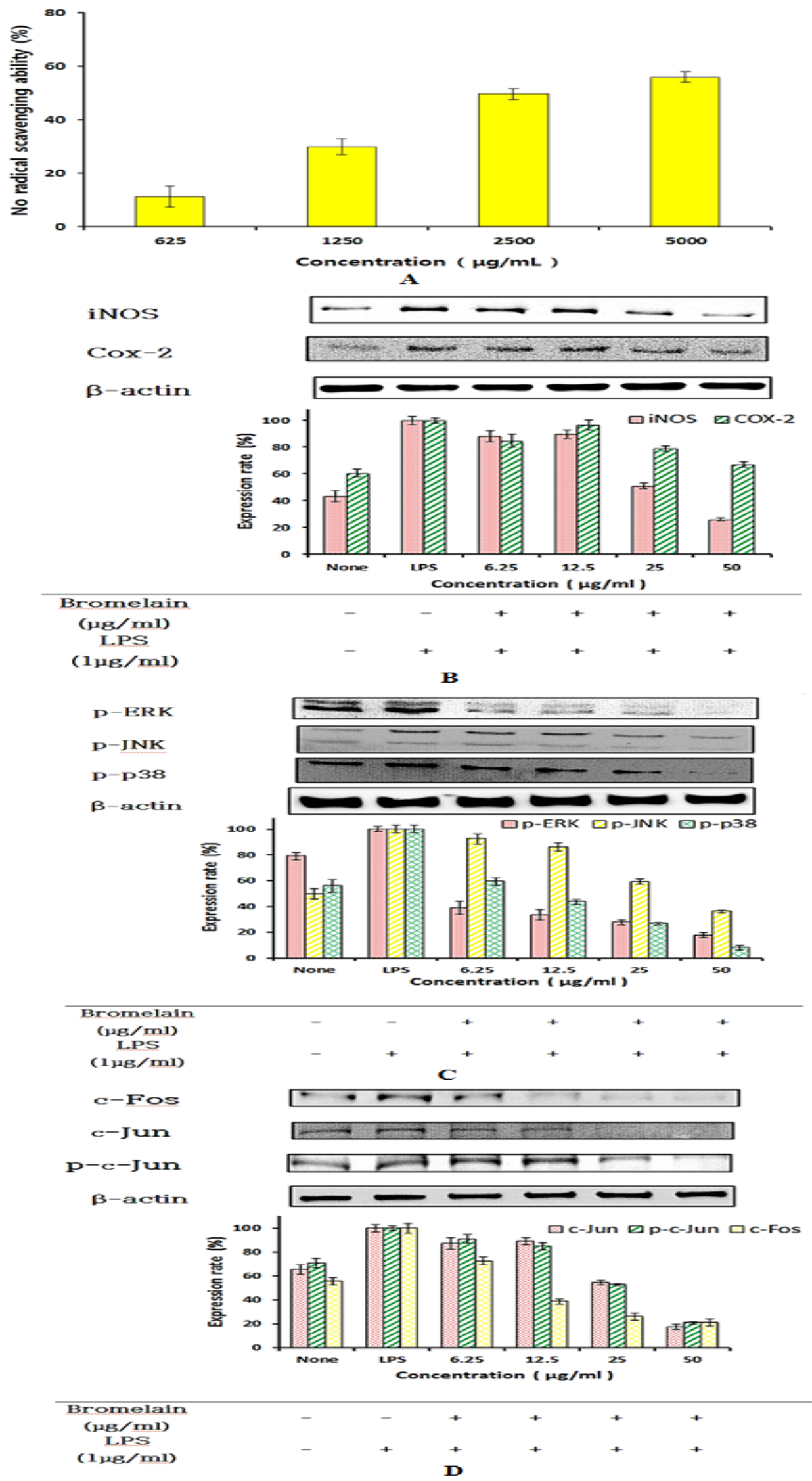

Figure 3. (A) The NO radical scavenging ability of bromelain. The NO radical scavenging ability of bromelain was calculated as $(\%)=(1-$ sample $\mathrm{A}_{420 \mathrm{~mm}} /$ control $\left.\mathrm{A}_{420 \mathrm{~nm}}\right) \times 100$. All data are expressed as mean \pm standard deviation $(\mathrm{n}=3) . P<0.05$, compared to the control.(B) Effect of bromelain on inflammatory gene expression (iNOS and COX-2) in LPS-stimulated RAW 264.7 macrophage cells. (C) Effect of bromelain on the phosphorylation of MAP kinases. (D) Effect of bromelain on AP-1 expression. RAW 264.7 macrophages were treated for $24 \mathrm{~h}$ with the indicated concentrations of bromelain before treatment with LPS ( $1 \mu \mathrm{g} / \mathrm{mL}$ for $30 \mathrm{~min})$. Following this, cell lysates were analyzed by western blotting using the indicated antibodies. $\beta$-actin was used as the control. The protein bands are representative of experiments, and the \% expression level indicates the level relative to LPS treated cells which were set as $100 \%$. All data are expressed as mean \pm standard deviation $(\mathrm{n}=3) . P<0.05$, compared to the control. 


\subsubsection{Effects of Bromelain on the AP-1 Expression in LPS-stimulated RAW 264.7 Cells}

The effect of bromelain on AP-1 signaling was also assessed in LPS-stimulated RAW 264.7 cells. The AP-1 complex consists of Jun and Fos family members. The transcriptional activity of AP-1, a heterodimer composed of c-Jun and c-Fos, is dependent on the degree of c-Jun phosphorylation and c-Fos expression. [26] Bromelain significantly suppressed the induction of c-Fos, having an inhibition of $25.80 \%$ at $25 \mu \mathrm{g} / \mathrm{mL}$ (Figure 3D). In addition, bromelain significantly reduced the c-Jun and phosphorylation of c-Jun.

\subsection{Effect of Bromelain on COX-2, TNF- $\alpha$ and iNOS mRNA Expression in RAW 264.7 Cells}

The expression of the mRNA encoding COX-2, TNF- $\alpha$, and iNOS were examined by RT-PCR. Cells in the blank group were treated with PBS, whereas cells in the
LPS group were treated with $1 \mu \mathrm{g} / \mathrm{mL}$ LPS. Bromelain decreased the expression of COX-2, TNF- $\alpha$, and iNOS in a dose-dependent manner (Figure 4). The repression of iNOS and COX-2 mRNA levels was consistent with the western blotting analysis. Thus, these experiments support the conclusion that bromelain exerts an anti-inflammatory effect due its ability to suppress the gene expression of COX-2, TNF- $\alpha$, and iNOS.

\subsection{Possible Mechanism by which Bromelain Inhibits Inflammation in LPS-stimulated RAW 264.7 Cells}

As shown in Figure 5, bromelain inhibits inflammatory gene expression by as a result of the inhibition of ERK phosphorylation and p-38 phosphorylation. In addition, the reduction of JNK phosphorylation likely leads to the inhibition of transcription of c-Fos and c-Jun family and a subsequent reduction in inflammatory cytokine production.
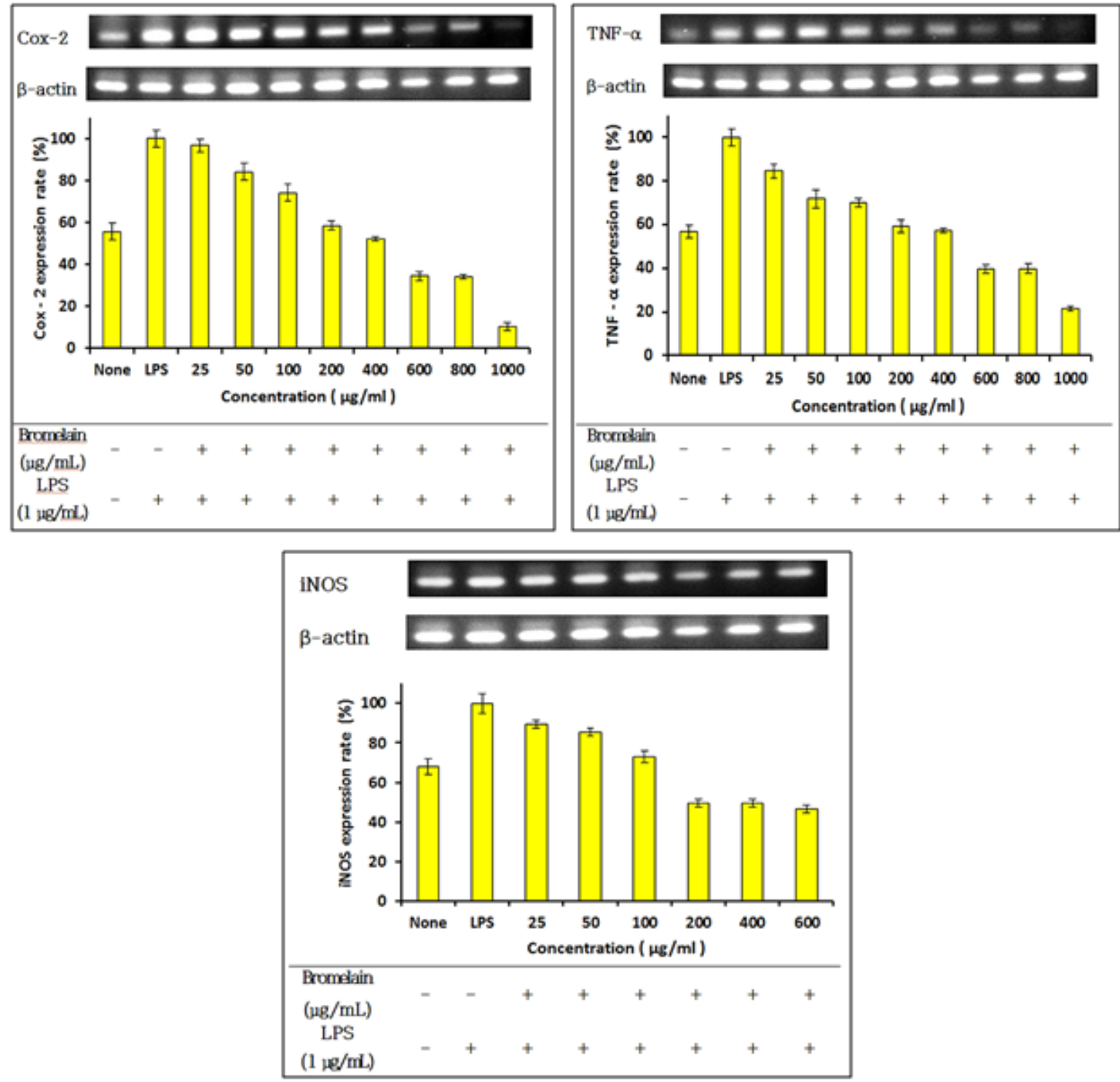

Figure 4. Effect of bromelain on the expression of inflammatory genes (Cox-2, TNFo, and iNOS) in LPS-stimulated RAW 264.7 macrophage cells. The cells were treated for $24 \mathrm{~h}$ with the indicated concentrations of bromelain before treatment with LPS $(1 \mu \mathrm{g} / \mathrm{mL})$. RT-PCR analysis of cDNA was performed using primers specific for Cox-2, TNF $\alpha$, and iNOS, with $\beta$-actin used for normalization. The PCR bands are representative of experiments and the densitometric graphs (\%) show the Cox-2, TNF $\alpha$, and iNOS ratios relative to the LPS-treated cells, which was set at $100 \%$ 


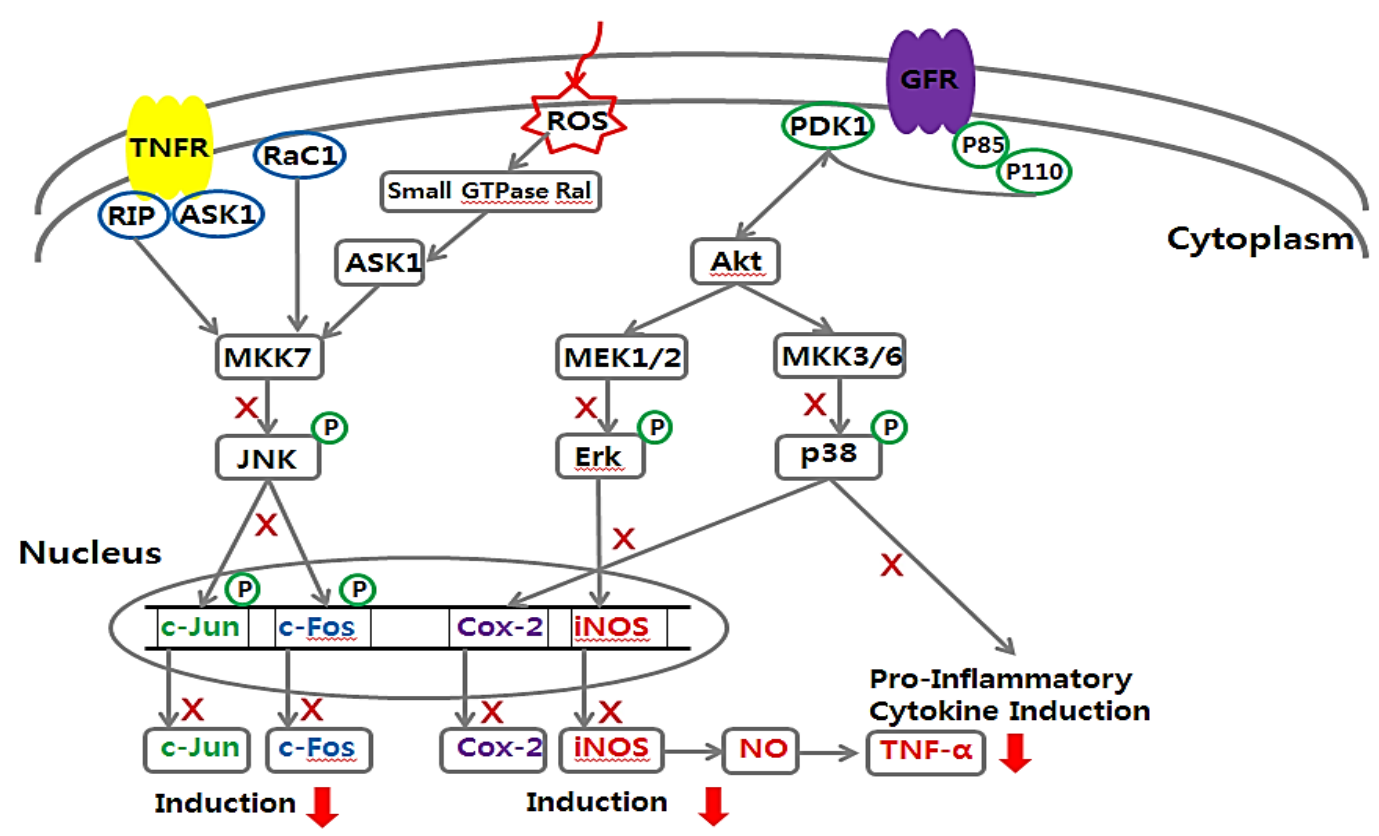

Figure 5. Diagrammatic representation of the effect of bromelain on the various pathways involved in inflammation

Medicinal plants are generally easy to cultivate, and have been consumed by humans for a long time. As a result, they are considered to be safe natural products and have been reported to contain antioxidants that can prevent the oxidative stress caused by reactive oxygen species and therefore might be useful in the prevention of diseases. In recent years, numerous studies have been carried out to isolate and characterize safe natural products that have anti-oxidative capacity. In this regard, bromelain, a widely used phyto-therapeutic member of the sulfhydryl proteolytic enzyme family, has been isolated from Ananas comosus and is of significant clinical interest. [27] Numerous studies have demonstrated its ability to treat immune related conditions as a result of its ability to reduce thrombogenesis platelet aggregation and surgical trauma. [28] Mechanistically, bromelain has been shown to be able to activate various innate immune cells including macrophages, dendritic cells, and natural killer cells. [29] Bromelain also can simultaneously both enhance and inhibit immune cell responses in vitro and in vivo through a stimulatory effect on accessory cells and a direct inhibitory on immune cells, respectively. [30]

In order to isolate bromelain enzymes to examine antioxidant and anti-inflammatory properties, the stem and bark of Ananas comosus were separated and cut into small pieces and dried at room temperature. After extraction with alcohol, a crude extract was obtained using saturated ammonium sulfate precipitation. The extract was dialyzed against ethanol and further purified by ion exchange chromatography using a DEAE-cellulose column. The final overall yield was $49 \%$ with a 17 fold purification, which was higher than the 14.2 fold purification. [18]

Oxygen is essential to maintain life although some of the oxygen is converted to reactive oxygen species (ROS). ROS species are unstable free radicals that cannot form one or more electron pairs in their outermost electron orbit. [31] Free radicals are produced during energy metabolism in the body and are removed by the efficient antioxidant defense mechanisms in vivo. However, when the balance of the antioxidant defense system is broken, oxidative stress is induced. Oxidative stress in the body is induced not only by respiration but also by ultraviolet rays, radiation and it is known to cause deterioration of vital function by inducing premature aging, inflammation. [32] ROS production in aerobic organisms occurs in all tissues of the body, constantly attacking the body's building blocks, eventually causing irreversible damage to cells and tissues. [33] The action of antioxidants serves to either suppress the production of free radicals or eliminate them.

The ABTS radical is a synthetic radical that is soluble in water or organic solvents, so the antioxidant activities of both polar and nonpolar samples can be measured. [34] The ABTS radical scavenging ability of bromelain increased up to $1000 \mu \mathrm{g} / \mathrm{mL}$. At $500 \mu \mathrm{g} / \mathrm{mL}$, its scavenging ability was $95.58 \%$, comparing very well with that of the positive control. These data indicate that bromelain possesses a strong anti-oxidant capability.

The DPPH radical scavenging assay is a simple and rapid method for measuring antioxidant activity of plants and food extracts. DPPH is stable organic nitrogen radical that has a deep purple color and it can be converted to the stable compound in the presence of a compound. [14] Similar to the data obtained for the ABTS radical scavenging activity, the DPPH scavenging activity of bromelain increased in a concentration dependent manner with the activity with $500 \mu \mathrm{g} / \mathrm{mL}$ bromelain being $68.07 \%$, which compared very well with the activity of the positive control. DPPH scavenging activity could be detected over a bromelain range of $12.5 \sim 500 \mu \mathrm{g} / \mathrm{mL}$. These data confirm that bromelain has strong antioxidant activity.

Among different ROS species, the highly reactive $\mathrm{H}_{2} \mathrm{O}_{2}$ molecule is harmful toxic to cells and induces cytotoxicity by producing such as $\mathrm{OH}$. [35] $\mathrm{H}_{2} \mathrm{O}_{2}$ is a liquid composed of hydrogen and oxygen, which can be freely mixed with water and easily permeates into the cell membrane when it enters the body. $\mathrm{H}_{2} \mathrm{O}_{2}$ scavenging activity of bromelain was measured over the range of $12.5 \sim 1000 \mu \mathrm{g} / \mathrm{mL}$. The hydrogen peroxide scavenging activity increased as the concentration of bromelain was increased up to 1000 $\mu \mathrm{g} / \mathrm{mL}$. At $500 \mu \mathrm{g} / \mathrm{mL}$, the hydrogen peroxide scavenging 
activity was $92.89 \%$, comparing very well with that of the positive control.

The antioxidant activity of SOD enzymes is one of the most important activities that protect cells from oxidative stress. [16] SOD-like activity of bromelain was measured over the range of $6.25 \sim 100 \mu \mathrm{g} / \mathrm{mL}$. The SOD-like activity of bromelain increased as the concentration increased up to $100 \mu \mathrm{g} / \mathrm{mL}$. At $100 \mu \mathrm{g} / \mathrm{mL}$, the SOD-like activity was $43.73 \%$, comparing well with the activity of the positive control.

Inflammation is an innate immune response caused by external stimuli such as bacterial infections. The inflammatory response results in an increase in the expression of iNOS and COX-2 in macrophages in response to cytokines. The action of these molecules causes classic inflammatory responses such as pain, swelling and fever. [36] NO is produced by the action of nitric oxide synthase. NO is involved in various physiological functions, such as blood coagulation, blood pressure control and immune reactions. However, when there is excessive NO present in the body, it can cause cell damage and cause an inflammatory reaction. When this inflammatory reaction occurs, the expression of iNOS is increased, and a large amount of NO is produced. NO radical scavenging ability of bromelain increased as the concentration increased up to $5000 \mu \mathrm{g} / \mathrm{mL}$. At the highest concentration of 5000 $\mu \mathrm{g} / \mathrm{mL}$, the NO radical scavenging ability of bromelain was $56.12 \%$. These data show that bromelain has the ability to remove NO. The free oxygen radical-like NO can act as a cytotoxic agent in pathological processes, particularly in inflammatory disorders. [37] Here, we also assessed the effect of bromelain on iNOS expression by western blotting. Bromelain treatment inhibited the LPSinduced iNOS expression in a dose-dependent manner over the range $6.26-50 \mu \mathrm{g} / \mathrm{mL}$.

One of the well-recognized molecular targets for chemoprevention is COX-2, which is abnormally upregulated in many premalignant and malignant tissues. [22] Kalra et al. have shown that application of bromelain inhibited COX-2 expression in mouse skin papilloma stimulated by DMBA-TPA treatment. [23] In addition, Huang et al. have shown that THP-1 cells treated with various concentrations of bromelain $(1-100 \mu \mathrm{g} / \mathrm{mL})$ and LPS $(1 \mu \mathrm{g} / \mathrm{mL})$ for $4 \mathrm{~h}$, had reduced levels of COX-2 mRNA levels, being reduced by $39 \%, 71 \%$, or $100 \%$ at 50 , 70 , and $100 \mu \mathrm{g} / \mathrm{mL}$ bromelain, respectively. [38] TNF- $\alpha$ is mainly secreted by activated macrophages, but is also secreted by various $\mathrm{T}$ cells, natural killer cells, and damaged neurons. [39] Huang et al. have shown that TNF$\alpha$ levels were reduced 28 to $49 \%$ by $50-100 \mu \mathrm{g} / \mathrm{mL}$ bromelain. [38] Likewise, in our study we showed that the expression of TNF- $\alpha$ mRNA was decreased in a dosedependent manner. Thus, these experiments support the conclusion that bromelain exerts its anti-inflammatory effects due its ability to suppress TNF- $\alpha$ gene expression in LPS-stimulated RAW 264.7 macrophage cells. Another signaling molecule associated with inflammation is MAP kinase. There are two classes of MAP kinase including, ERK and JNK. [40] ERK is involved in cell proliferation and differentiation, and is activated by stimuli, such as growth factors and cytokines, and following a viral infection. JNK, in contrast, are known to be involved in cell differentiation and apoptosis. Kalra et al. have shown that treatment with DMBA-TPA significantly enhances the phosphorylation of MAPK resulting in its translocation to the nucleus. This translocation was inhibited by bromelain treatment which caused the de-phosphorylation of MAPK. Furthermore, treatment of mouse skin with DMBA-TPA induced the phosphorylation of ERK-1/2, and bromelain treatment inhibited this phosphorylation which led to the inhibition of ERK-1/2 translocation to the nucleus. [23] Huang et al. have found that bromelain suppressed phosphorylation of ERK1/2, JNK at concentrations of $50-100 \mu \mathrm{g} / \mathrm{mL}$. [38] Accordingly, we assessed the activation of c-Fos and c-Jun. Bromelain significantly suppressed the expression of c-Fos and reduced its expression by $25.80 \%$ at a concentration of $25 \mu \mathrm{g} / \mathrm{mL}$. The reduction in JNK phosphorylation probably leads to the inhibition of transcription of the c-Fos and c-Jun family. In addition, bromelain significantly reduced the phosphorylation of cJun and c-Jun. Bromelain inhibited the expression of iNOS and COX-2 presumably as a result of inhibiting ERK and p-38 phosphorylation.

In recent years, there has been a growing interest in identifying physiologically active substances that pose little or no risk of side effects and many physiologically active substances have been identified. Studies on effective inflammation mitigation and inhibition mechanisms that inhibit NO using physiologically active substances in oral condition have been conducted. In addition, there is a demand for development of a drug, which has excellent anti-inflammatory effects and can suppress inflammation without side effects. In response to this, we have shown that bromelain has a remarkable anti-inflammatory activity, producing effects on numerous molecules in inflammatory pathways so that it could be a potential therapeutic strategy to treat oral diseases like stomatitis.

In this study, we have clearly demonstrated that bromelain isolated from an Ananas comosus extract has a significant anti-oxidant activity, as well as anti-inflammatory ability. It is thought that molecules with both an anti-oxidative effect and an anti-inflammatory effect should be effective in treating diseases caused by oxidative stress as a result of ROS generation as well as in inflammatory diseases. This is the first study that advances the mechanistic knowledge of herbal remedy that targets oral environment. Furthermore, we have attempted to identify a natural substance rather than synthetic chemical agent. Based on the study, more systematic studies should be conducted in the future and it is hoped that it bromelain will be a useful natural product that could be used as a general anti-oxidant or an antiinflammatory medicine which is safe and effective. In other words, our present findings demonstrate that bromelain could be a novel therapeutic strategy for in antioxidant and anti-inflammatory natural medicine.

\section{Funding Sources}

This research did not receive any specific grant from funding agencies in the public, commercial, or not-forprofit sectors. 


\section{Conflict of Interest}

The authors declared no conflict of interest.

\section{Abbreviations}

AA: Ascorbic acid ABTS: 2, 20-Azinobis-3-ethylbenzothiazoline-6-sulfonic acid

AP-1: Activator protein-1

BHA: Butylated hydroxyanisole

BHT: Butylated hydroxytoluene

BR: Bromelain

COX-2: Cyclooxygenase-2

DMED: Dulbecco's Modified Eagle Medium

DMBA-TPA: 7,12-dimethylbenz(a)anthracene

(DMBA)-initiated and 12-O-tetradecanoylphorbol-13-

acetate (TPA)

DPPH: 1,1-diphenyl-2-picrylhydrazyl

ERK: Extracellular signal-regulated kinase

FBS: Fetal Bovine Serum

iNOS: inducible nitric oxide synthase

JNK: c-Jun N-terminal kinase

LPS: Lipopolysaccharide

MAPK: Mitogen activating protein kinase

NO: Nitric Oxide

ROS: Reactive oxygen species

RPMI: Roswell Park Memorial Institute medium

RT-PCR: Reverse transcription-polymerase chain reaction SOD: Superoxide dismutase

\section{References}

[1] Paroulek AF, Jaffe M, Rathinavelu A. The effects of the herbal enzyme bromelain against breast cancer cell line GI-101A. Doctoral dissertation, Nova Southeastern University (2010).

[2] Castell JV, Friedrich G, Kuhn CS, Poppe GE. Intestinal absorption of undegraded proteins in men: presence of bromelain in plasma after oral intake. Am J Physiol Gastrointest Liver Physiol. 273: G139-G146 (1997).

[3] Gaciong Z, Paczek L, Bojakowski K, et al. Beneficial effect of proteases on allograft arteriosclerosis in a rat aortic model. Nephrol Dial Transplant. 11:987-989 (1996).

[4] Targoni OS, Tary-Lehmann M, Lehmann PV. Prevention of murine EAE by oral hydrolytic enzyme treatment. J Autoimmun. 12: 191-198 (1999).

[5] Rovenska E, Svik K, Stancikova M, Rovensky J. Inhibitory effect of enzyme therapy and combination therapy with cyclosporin on collagen-induced arthritis. Clin Exp Rheumatol. 19: 303-309 (2001).

[6] Majima M, Nishiyama K, Iguchi Y, et al. Determination of bradykinin-(1-5) in inflammatory exudate by a new ELISA as a reliable indicator of bradykinin generation. Inflamm Res. 45: 416-423 (1996).

[7] Houck JC, Chang CM, Klein G. Isolation of an effective debriding agent from the stems of pineapple plants. Int J Tissue React. 5:125-134 (1983).

[8] Abbasi HS, Sabouni F, Moghimi A, Ansari MS, Tafreshi AP. Reduction of NO production in LPS-stimulated primary rat microglial cells by bromelain. J Cell Mol Res. 3:57-65 (2012).

[9] Hale LP, Greer PK, Trinh CT, Gottfried MR. Treatment with oral bromelain decreases colonic inflammation in the IL-10-deficient murine model of inflammatory bowel disease. Clin Immunol. 116: 135-142 (2005).

[10] Liu D, Sheng J, Li Z, et al. Antioxidant activity of polysaccharide fractions extracted from Athyrium multidentatum (Doll.) Ching. Int J Biol Macromol. 56: 1-5 (2013).
[11] Pervin M, Hasnat MA, Lim BO. Antibacterial and antioxidant activities of Vaccinium corymbosum L. leaf extract. Asian Pac J Trop Dis. 3:444-453 (2013)

[12] Circu ML, Aw TY. Reactive oxygen species, cellular redox systems, and apoptosis. Free Radic Biol Med. 48:749-762 (2010).

[13] Re R, Pellegrini N, Proteggente A, et al. Antioxidant activity applying an improved ABTS radical cation decolorization assay. Free Radic Biol Med. 26:1231-1237 (1999).

[14] Blois MS. Antioxidant determinations by the use of a stable free radical. Nature. 181:1199-1200 (1958).

[15] Jayaprakasha GK, Rao LJ, Sakariah KK. Antioxidant activities of flavidin in different in vitro model systems. Bioorganic Med Chem. 12:5141-5146 (2004).

[16] Marklund S, Marklund G. Involvement of the superoxide anion radical in the autoxidation of pyrogallol and a convenient assay for superoxide dismutase. FEBS J. 47:469-474 (1974).

[17] Gray JI, Dugan LR. Inhibition of n-nitrosamine formation in model food systems. J Food Sci. 40:981-984 (1975).

[18] Silverstein RM, Kezdy FJ. Characterization of the pineapple stem proteases. Arch Biochem Biophys 167:678-686 (1975)

[19] Rice-evans CA, Miller NJ, Bolwell PG, Bramley PM, Pridham JB: The relative antioxidant activities of plant-derived polyphenolic flavonoids. Free Radic Res 22:375-383 (1995).

[20] Heo JC, Park JY, An SM, et al: Anti-oxidant and anti-tumor activities of crude extracts by Gastrodia elata Blume. Korea J Food Preserv 13:83-87 (2006)

[21] Singh VK, Mehrotra S, Narayan P, Pandey CM, Agarwal SS: Modulation of autoimmune diseases by nitric oxide. Immunol Res 22:1-19 (2000).

[22] Kim SO, Kundu JK, Shin YK, et al: [6]-Gingerol inhibits COX-2 expression by blocking the activation of p38 MAP kinase and NF$\kappa \mathrm{B}$ in phorbol ester-stimulated mouse skin. Oncogenes 24:25582567 (2005).

[23] Kalra N, Bhui K, Roy P, et al: Regulation of p53, nuclear factor $\kappa \mathrm{B}$ and cyclooxygenase-2 expression by bromelain through targeting mitogen-activated protein kinase pathway in mouse skin. Toxicol Appl Pharmacol 226:30-37 (2008).

[24] Aktan F: iNOS-mediated nitric oxide production and its regulation. Life Sci 2004; 75: 639-653.

[25] Alderton WK, Cooper CE, Knowles RG: Nitric oxide synthases: structure, function and inhibition. Biochem J 357: 593-615 (2001).

[26] Yang SH, Sharrocks AD, Whitmarsh AJ: Transcriptional regulation by the MAP kinase signaling cascades. Gene 320: 3-21 (2003).

[27] Dave S, Dkhar HK, Singh MP, et al: Hexafluoroisopropanol-induced helix-sheet transition of stem bromelain: Correlation to function. Int J Biochem Cell Biol 42:938-947 (2010).

[28] Maurer HR: Bromelain: biochemistry, pharmacology and medical use. Cell Mol Life Sci 58:1234-1245 (2001).

[29] Engwerda CR, Andrew D, Murphy M, Mynott TL: Bromelain activates murine macrophages and natural killer cells in vitro. Cell Immunol 210: 5-10 (2001).

[30] Engwerda CR, Andrew D, Ladhams A, Mynott TL: Bromelain modulates $\mathrm{T}$ cell and $\mathrm{B}$ cell immune responses in vitro and in vivo. Cell Immunol 210: 66-75 (2001).

[31] Gibson GR, Roberfroid MB: Dietary modulation of the human colonic microbiota: introducing the concept of prebiotics. J Nutr 125:1401 (1995).

[32] Tomimori Y, Tanaka Y, Goto M, Fukuda Y: Repeated topical challenge with chemical antigen elicits sustained dermatitis in NC/Nga mice in specific-pathogen-free condition. J Invest Dermatol 124: 119-124 (2005).

[33] Misra HP, Fridovich I: The role of superoxide anion in the autoxidation of epinephrine and a simple assay for superoxide dismutase. J Biol Chem 247: 3170-3175 (1972).

[34] Awika JM, Rooney LW, Wu X, Prior RL, Cisneros-Zevallos L: Screening methods to measure antioxidant activity of sorghum (Sorghum bicolor) and sorghum products. J Agric Food Chem 51: 6657-6662 (2003).

[35] Hoffmann MR, Martin ST, Choi W, Bahnemann DW: Environmental applications of semiconductor photocatalysis. Chem Rev 95: 69-96 (1995).

[36] Kim BH, Lee YT, Kang KH: Codonopsis lanceolata inhibits inflammation through regulation of MAPK in LPS-stimulated RAW264. 7 cells. J Physiol \& Pathol Korean Med 24 (2010).

[37] Alderton WK, Cooper CE, Knowles RG: Nitric oxide synthases: structure, function and inhibition. Biochem J 357:593 (2001). 
[38] Huang JR, Wu CC, Hou RCW, Jeng KC: Bromelain inhibits lipopolysaccharide-induced cytokine production in human THP-1 monocytes via the removal of CD14. Immunol Invest 37: 263-277 (2008).

[39] Liu T, Clark RK, McDonnell PC, et al: Tumor necrosis factor-alpha expression in ischemic neurons. Stroke 25:1481-1488 (1994).
[40] Johnson GL, Lapadat R: Mitogen-activated protein kinase pathways mediated by ERK, JNK, and p38 protein kinases. Science 298: 1911-1912 (2002). 